Q. Wang, et al., Int. J. Sus. Dev. Plann. Vol. 9, No. 5 (2014) 647-657

\title{
PROCESS ANALYSIS OF THE WASTE BAMBOO BY USING POLYETHYLENE GLYCOL SOLVENT LIQUEFACTION
}

\author{
Q. WANG ${ }^{1}$, Q. CHEN ${ }^{1}$, Q. QIAO ${ }^{1} \&$ K. SUGIYAMA ${ }^{2}$ \\ ${ }^{1}$ Graduate School of Science and Engineering, Saitama University, Japan. \\ ${ }^{2}$ Hachinohe National College of Technology, Japan.
}

\begin{abstract}
Solvent liquefaction process is one of the promising techniques for the effective utilization of waste woody biomass. In the liquefaction process, waste woody biomass such as waste bamboo could be converted to liquid reactive materials for developing biomass-based materials since waste bamboo has an advantage of providing the liquefied products with a small range of variances. The components of liquefied waste bamboo released during the liquefaction reaction with the polyethylene glycol 400 (PEG 400) solvent is highly acidic in the presence of mineral acid catalysts. Therefore, this study was carried out for analyzing the behavior of the liquefied residues (LRs) from waste bamboo during the solvent liquefaction process. The LRs produced during the liquefaction process were measured and related to different liquefied conditions. The change in the morphological surface of the liquefied waste bamboo samples was observed by a scanning electron microscope. The chemical changes in the functional groups were analyzed by a Fourier transform infrared spectrometer. The crystalline structure of liquefied waste bamboo samples was determined by X-ray diffraction. The chemical composition analysis and particle size distribution of liquefied waste bamboo samples were also carried out to confirm the results. It was found that the efficiency of liquefaction process can be improved by increasing the temperature and the amount of acid catalysts, although condensation reaction occurred under the liquefaction condition with high temperature. The liquefaction period of lignin was significantly shorter than one of cellulose in the solvent liquefaction process with PEG 400. Moreover, it is indicated that the progress of liquefaction process may be prevented by smaller particle sizes of cellulose collected in liquefied bamboo.
\end{abstract}

Keywords: Bamboo, FT-IR, gel permeation chromatography, liquefaction, PEG 400, SEM, X-ray diffraction.

\section{INTRODUCTION}

Bamboo, as a significant biomass resource, has been used in many fields of biomass utilization. It is also used for making furniture, food steamers, chopsticks, and paper pulp. Bamboo grows naturally in the tropical, subtropical, and temperate regions around the world. Bamboo is fast-growing, economic, and of high cultural significance in East Asia and South East Asia [1]. Liquefaction technology is an effective method for the decomposition of lignocellulose biomass. The liquefied products were used for the preparation of different biomass-based materials [2, 3]. Solvent liquefaction process is a promising technique for the effective production of waste biomass. The waste biomass could be converted to liquid reactive materials for developing biomass-based materials.

Lin and co-workers had attempted to explain the liquefaction reaction mechanism of cellulose with phenol under the acid-catalyzed conditions [4]. It was found that the yields of various products were dependent on the reaction conditions. The structure and properties of the liquefied products at the later stage of liquefaction reaction might be changed by controlling the reaction time and other conditions. As the target products, biomass-based polyurethane films and Novolak PF resins were prepared, and their structures and properties were discussed [5-8]. The microwave and supercritical solvent methods were used for heating in the liquefaction process effectively [9-11]. However, condensation reaction had occurred due to a change in the experimental conditions such as solvent/ cellulose addition ratios in the study of cellobiose liquefaction [12]. A previous study reported that an insoluble residue was formed when cellulose and lignin coexisted [13]. However, the mechanism of formation of condensed residues still needs to be clarified [14] and is driving the research to 
overcome the limitations of physical and mechanical properties of resin products [15]. Furthermore, it needs longer time to liquefy a biomass with higher crystallinity index such as bamboo [1]. It is known that bamboo fiber has high strength, low elongation, and high crystalline properties. The solvent liquefaction will become slow and inefficient due to the high crystalline property. It is necessary to analysis the behaviour of the liquefied residues (LRs) and the mechanism of the condensation reaction during the liquefaction process. It is therefore necessary to understand the changes in bamboo residues in the liquefaction process in order to promote that process.

In this study, waste bamboo planted in Japan was used in the liquefaction experiment. The LRs produced during the liquefaction process were measured under the liquefaction condition. The surface changes of bamboo were observed by a scanning electron microscope (SEM). The changes in the functional groups were analyzed by a Fourier transform infrared spectrometer (FT-IR) and the changes in the crystalline structures in liquefied bamboo residues were determined by an X-ray diffraction (XRD). The average molecular weight of the liquefied product was analyzed by gel permeation chromatography. In this paper, more experimental results are newly reported, and deepened work has done to overcome the debate on contents of the conference paper published in 4th International Conference on Energy and Sustainability [16].

\section{MATERIALS AND METHODS}

\subsection{Materials}

The waste bamboo powder was purchased from a waste treatment factory in Japan. All samples of bamboo were dried in an oven at $105^{\circ} \mathrm{C}$ for 24 hours to remove the moisture. The dried bamboo powder were milled in a smashing equipment and retained at the size ranging from 1 to $2 \mathrm{~mm}$. The cellulose samples (CAS No: 9004-34-6 MP Blomedicais, LLC) were used as the simulated bamboo material, and $95 \mathrm{wt} \%$ sulfuric acid was used as an acidic catalyst. The average molecular weight of polyethylene glycol was 400 (PEG 400), and other reagents were prepared with the analytical grade reagents (Wako Pure Chemicals, Co. Ltd., Japan). All chemicals used in this study were reagent grade and were used without further purification.

\subsection{Liquefaction experiment and measurement of LR}

The waste bamboo powder was used in the liquefaction experiment and the weight to charge ratio of bamboo and PEG 400 was $1 / 4$ and 1/8, respectively (including $10 \mathrm{wt} \%$ glycerin). The reaction temperatures were set at $120^{\circ} \mathrm{C}$ and $150^{\circ} \mathrm{C}$ by oil bath. The raw materials were put into a $500 \mathrm{ml}$ three-necked flask equipped with a stirrer. The catalyst of varying concentration from $3 \mathrm{wt} \%$ to $10 \mathrm{wt} \%$ was added to the reactant at the start of the reaction, and methanol was added to the liquefied products to stop the reaction. The liquefied bamboo was then diluted with methanol, and Whatman filter paper (No. 40) was used to collect the LRs. The amount of solvent-insoluble residue was calculated by eqn (1).

$$
\text { LR content }(\mathrm{wt} \%)=(\text { solvent-insoluble residue } / \text { raw material }) \times 100
$$

\subsection{Chemical composition analysis and particle size of liquefied bamboo residue}

The remaining moisture and ash content of the bamboo sample after combustion were measured according to the industrial standard method (JIS-M8812) while bamboo powder was heated at $900^{\circ} \mathrm{C}$ under controlled conditions for the measurement of ash content. The amount of $1 \% \mathrm{NaOH}$ soluble 
components, methanol-benzene-soluble components, holocellulose, and lignin was determined by timber analytical manual [17]. The liquefied bamboo was dried in an oven at $105^{\circ} \mathrm{C}$ for 24 hours. Then, the samples of different sizes $1-0.5 \mathrm{~mm}, 0.5-0.25 \mathrm{~mm}, 0.25-0.125 \mathrm{~mm}$, and $0.125-0.075 \mathrm{~mm}$ were prepared by sieving.

\subsection{Morphological observation by an SEM}

The morphological changes of bamboo samples and LRs were observed by an SEM (Model S-2400; Hitachi Co. Ltd., Japan) at an acceleration voltage of $15 \mathrm{kV}$.

\subsection{FT-IR analysis}

The variations in the functional groups of bamboo residues were measured using an FT-IR spectrometer (Model IR-6100; Jasco Co. Ltd., Japan). All the infrared spectra were recorded in absorbance units within the range of $4000-400 \mathrm{~cm}^{-1}$. Absorbance area was calculated by Spectrum Manager Ver.2 software (Jason Corporation).

\subsection{XRD analysis}

The 002 reflection for crystallite height $002\left(\mathrm{I}_{002}\right)$ and amorphous reflection for amorphous height $\left(\mathrm{I}_{\mathrm{am}}\right)$ were used to calculate the apparent crystalline index (Apparent Cr.I.) (eqn (2)) using an Ultima III $\mathrm{X}$-Ray diffractometer (Rigaku Co. Ltd., Japan) [17-19]. Ni-filtered $\mathrm{Cu}-\mathrm{K} \alpha$ radiation $(\lambda=0.1542 \mathrm{~nm})$ generated the voltage of $40 \mathrm{kV}$ and current was set at $40 \mathrm{~mA}$. Intensities ranging from $10^{\circ}$ to $40^{\circ}$ with $4 \%$ min scan speed were set for total XRD analysis experiment.

$$
\text { Apparent Cr.I. }=\left(\mathrm{I}_{002}-\mathrm{I}_{\mathrm{am}}\right) / \mathrm{I}_{002} \times 100
$$

\subsection{Gel permeation chromatography analysis}

The liquefied product was dissolved in $0.1 \%(\mathrm{w} / \mathrm{v})$ tetrahydrofuran (THF) and filtered through 0.45 $\mu \mathrm{m}$ membrane. THF solution was used as eluent and the flow rate was $1.0 \mathrm{ml} / \mathrm{min}$. The average molecular weight of the samples were determined by a gel permeation chromatography system (RI detector: RI-2031 plus, HPLC pump: PU-2080 plus, and Column thermostat: CO-2060 Plus; Jasco Co. Ltd., Japan), equipped with a KD806L gel columns (Shodex, Showa Denko K.K., Japan) in series at $40^{\circ} \mathrm{C}$. The average molecular weights of samples were calculated by Jasco-Borwin software.

\section{RESULTS AND DISCUSSIONS}

\subsection{Liquefied waste bamboo samples under different experimental conditions}

\subsubsection{Characteristic of LR}

The ash content of the LR was measured after combustion of the bamboo sample according to the industrial standard method presented in Table 1. The moisture content was found to be $9.3 \mathrm{wt} \%$ in the flesh part of the bamboo and $14.4 \mathrm{wt} \%$ in the bark part, which was determined by measuring the weight loss after drying the sample at $105^{\circ} \mathrm{C}$. Ash content was found to be $2.2 \mathrm{wt} \%$, which was measured by heating the bamboo powder at $900^{\circ} \mathrm{C}$ under carefully controlled conditions. $26.9 \mathrm{wt} \%$ of $1 \% \mathrm{NaOH}$ soluble composition and $7.5 \mathrm{wt} \%$ of methanol-benzene-soluble composition were also determined in this study. According to the results, the amount of holocellulose content was similar in the flesh and bark part of the bamboo. 
Table 1: Industrial analysis and component analysis of bamboo (wt \%).

\begin{tabular}{lcccccc}
\hline $\begin{array}{l}\text { Air-dried } \\
\text { sample }\end{array}$ & Moisture & Ash & $\begin{array}{c}1 \% \mathrm{NaOH} \\
\text { soluble }\end{array}$ & $\begin{array}{c}\text { (Methanol-benzene) } \\
\text { soluble }\end{array}$ & Holocellulose & Lignin \\
\hline Flesh part & 9.3 & 2.2 & 26.9 & 7.5 & 77.4 & 14.8 \\
Bark part & 14.4 & 3.8 & 29.6 & 11.9 & 68.9 & 18.9 \\
\hline
\end{tabular}
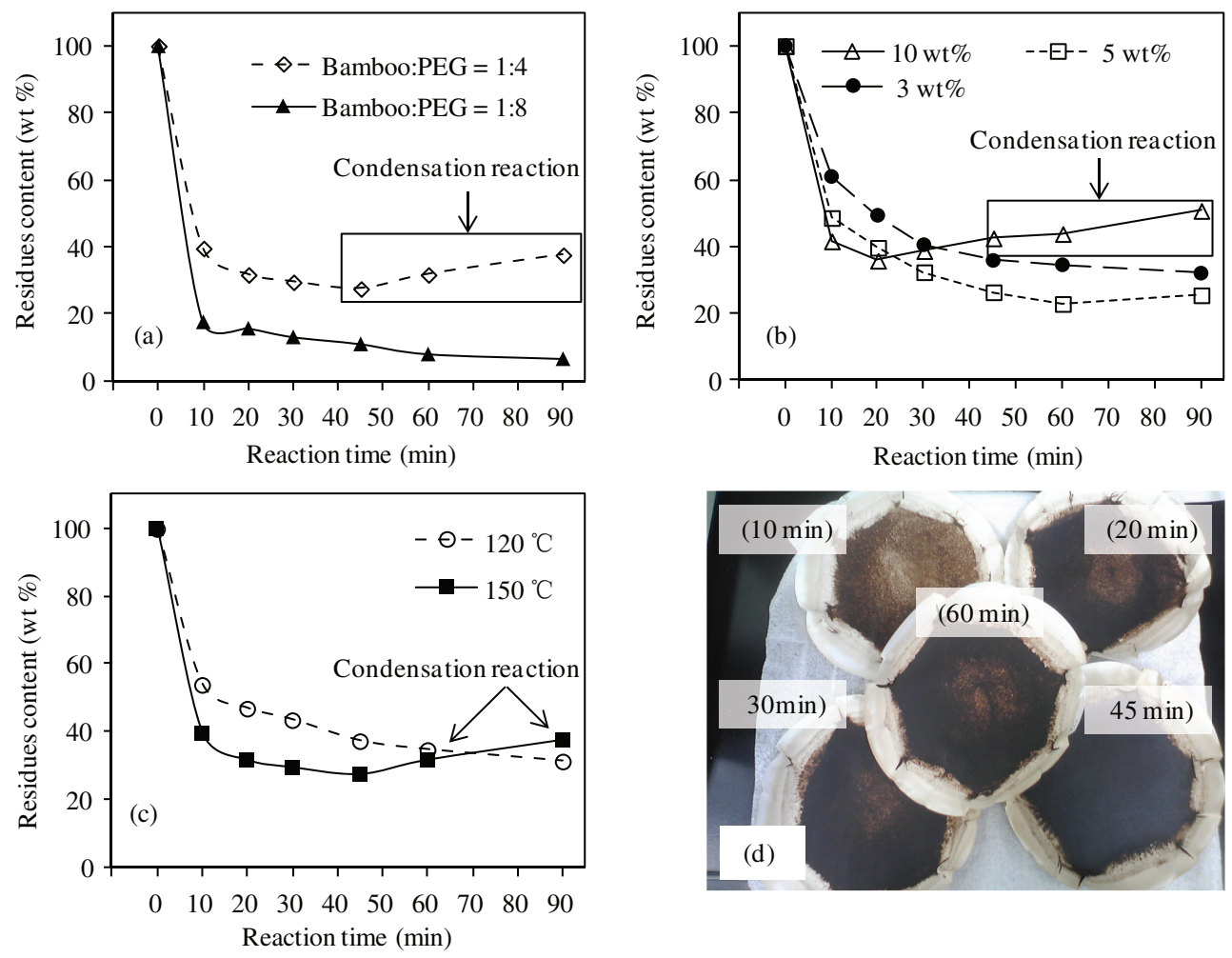

Figure 1: Liquefaction residue content of bamboo at different condition. (a) Ratio of bamboo to solvent; (b) different amount of sulfuric acid; (c) effect of temperature; (d) liquefied residues and condensation products according the conditions of (c).

The mixture of waste bamboos was used as the waste part in the liquefaction experiment for determining the suitable experimental condition. The amount of LR was used as a significant index to evaluate the performance of liquefied bamboo in the solvent liquefaction reaction. Three major liquefaction conditions were considered in this experiment. Reaction temperature and the amount of sulfuric acid increased the reaction speed as well as the efficiency. The amount of raw material in solvent was another index which helps understanding the consumption of the solvent [12]. The considerable reaction had occurred during liquefaction process when the experimental conditions such as solvent/cellulose addition ratio (Fig. 1a) were changed. Figure $1 \mathrm{~b}$ shows the liquefaction rate of bamboo at different concentrations of sulfuric acid within $90 \mathrm{~min}$ at $120^{\circ} \mathrm{C}$. 
Initially, only fewer residues were obtained. However, the residue content was increased from $30 \mathrm{~min}$. The residues coexisted by condensation reaction are indicated by dotted line in Fig. $1 \mathrm{~b}$. Cellulose was gradually converted to levulinic acid derivatives after the conversion of lignin into solvent-soluble compounds in the early stage of bamboo liquefaction. Then, the mixture of levulinic acid derivatives and aromatic compounds reacted and converted to the solvent-soluble residue. The result indicated that the insoluble residue was formed when cellulose and lignin coexisted [20]. When $10 \mathrm{wt} \%$ sulfuric acid of solvent was added during the reaction, more residues were obtained, which indicated that the presence of insoluble residue in the liquefied products. This problem may affect the mechanical properties of resin products from liquefied biomass [15]. Increasing reaction temperature also could lead to condensation reaction (Fig. 1c). The black residues were increased in filter (Fig. 1d).

Yamada et al. found that the condensation reaction disappeared during wood and cellulosic liquefaction while glycerin was added as a reagent into the liquefaction system at the ratios of 1:0 and 3:7 (glycerin:PEG 400, w/w) [21]. However, the condensation reaction reoccurred during wood liquefaction when the ratio of glycerin to PEG 400 was decreased to 1:5. This result was similar to that reported in this study (bamboo:solvent $=1: 8$, see Fig. 1a), which indicated that the solvent consumption was one of the causes for condensation reaction. Condensation reaction occurred when the charge ratios were 2 and 4, but it was not observed at the larger charge ratios such as 6 and 10 [22]. Condensation did not occur in the process of cellulose and lignin liquefaction independently $[13,20]$. However, the longer reaction time, one of the significant conditions, could lead to condensation reaction during cellulosic liquefaction due to the special molecular arrangement of cellulose, which was different from that of lignin and hemicellulose [14]. The lower and soft reaction conditions may be attributed to condensation of degraded lignin components. It could be concluded that an increase in the temperature and the amount of the acid catalyst could improve the efficiency of liquefaction process. However, it was major factor for the condensation reaction to occur.

\subsubsection{Surface observation of LRs and raw bamboos by SEM}

The SEM image of LR (obtained in $5 \mathrm{~min}$ ) and raw bamboos at $120^{\circ} \mathrm{C}$ are shown in Fig. 2. The image shows that the liquefied cellulose particles were not dissolved uniformly. This randomness reaction made the speed of the liquefaction reaction irregular.
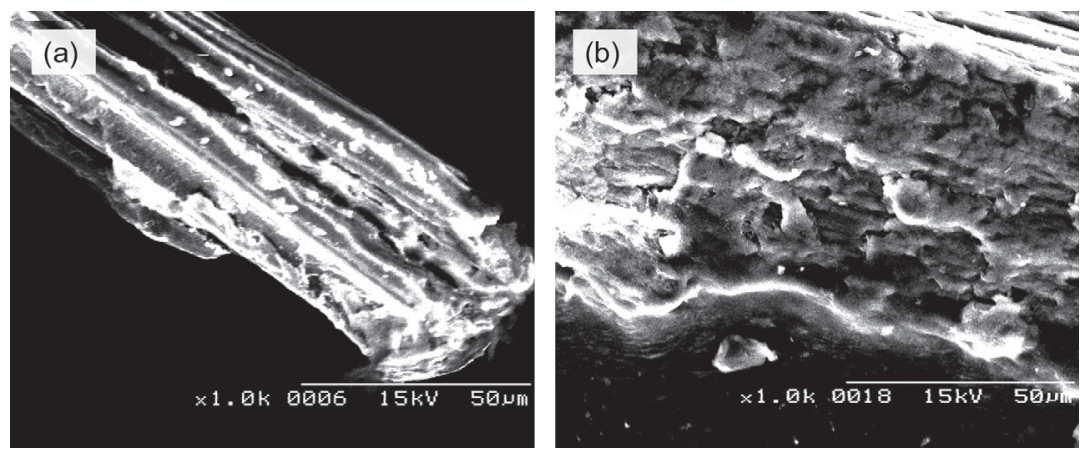

Figure 2: Comparative study of bamboo and LRs at $120^{\circ} \mathrm{C}$ in $5 \mathrm{~min}$ (a) bamboo; (b) LRs (bamboo: $\mathrm{PEG}=1: 4$, sulfuric acid $5 \mathrm{wt} \%$ ) 


\subsection{Process analysis of liquefied waste bamboo samples}

3.2.1 Observation of functional group changing behavior by FT-IR

To determine the functional groups changing behavior in bamboo and liquefied bamboo, the spectra of functional groups in bamboo were observed by FT-IR spectrometer. The main functional groups of the liquefied products are listed in Table 2. The similar peak was observed, which was compared with the peak of raw bamboo and its $5 \mathrm{~min}$ LRs at $120^{\circ} \mathrm{C}$. The spectrometer peak of cellulose as model substance also is also shown in Fig. $3\left(120^{\circ} \mathrm{C}\right)$. The peak was similar to the peak of bamboo and its $30 \mathrm{~min}$ residues because the lignin was liquefied rapidly [23]. This result suggested that

Table 2: Functional groups of bamboo and liquefied bamboo.

\begin{tabular}{|c|c|c|c|}
\hline $\begin{array}{l}\text { Absorption band } \\
\left(\mathrm{cm}^{-1}\right)\end{array}$ & Assignment & Origin from & References \\
\hline $3500-3100$ & $\mathrm{O}-\mathrm{H}$ & Hydroxide & \\
\hline $2908 ; 2907$ & $\mathrm{CH} ; \mathrm{CH}_{2}$ & $\begin{array}{l}\mathrm{CH} \text { and } \mathrm{CH}_{2} \text { stretching vibration of aliphatic } \\
\text { hydrocarbons }\end{array}$ & {$[24]$} \\
\hline $1743 ; 1736$ & $\mathrm{C}=\mathrm{O}$ & Acetyl group or carboxyl group & \\
\hline 1716 & $\mathrm{C}=\mathrm{O}$ & $\begin{array}{l}\text { Carboxyl group stretching conjugated carbonyl } \\
\text { group }\end{array}$ & [7] \\
\hline $1600 ; 1510$ & $\mathrm{C}=\mathrm{C}$ & The aromatic ring of the lignin & {$[25]$} \\
\hline $1605 ; 1508 ; 1423$ & $\mathrm{C}-\mathrm{H}$ & $\mathrm{C}-\mathrm{H}$ of the aromatic ring & [7] \\
\hline $1430 ; 1370$ & $\mathrm{C}-\mathrm{H}$ & It is a group of $\mathrm{CH}_{2}$ & [3] \\
\hline 1151 & $\mathrm{C}-\mathrm{O}-\mathrm{C}$ & $\begin{array}{l}\text { C-O-C symmetric stretching vibration of lignin } \\
\beta-O-4 \text { ether bond }\end{array}$ & {$[24]$} \\
\hline 1100 & $\mathrm{C}-\mathrm{O}$ & C-O functional group of cellulose & [3] \\
\hline 830 & $=\mathrm{C}-\mathrm{H}$ & Aromatic $\mathrm{C}-\mathrm{H}$ & \\
\hline
\end{tabular}
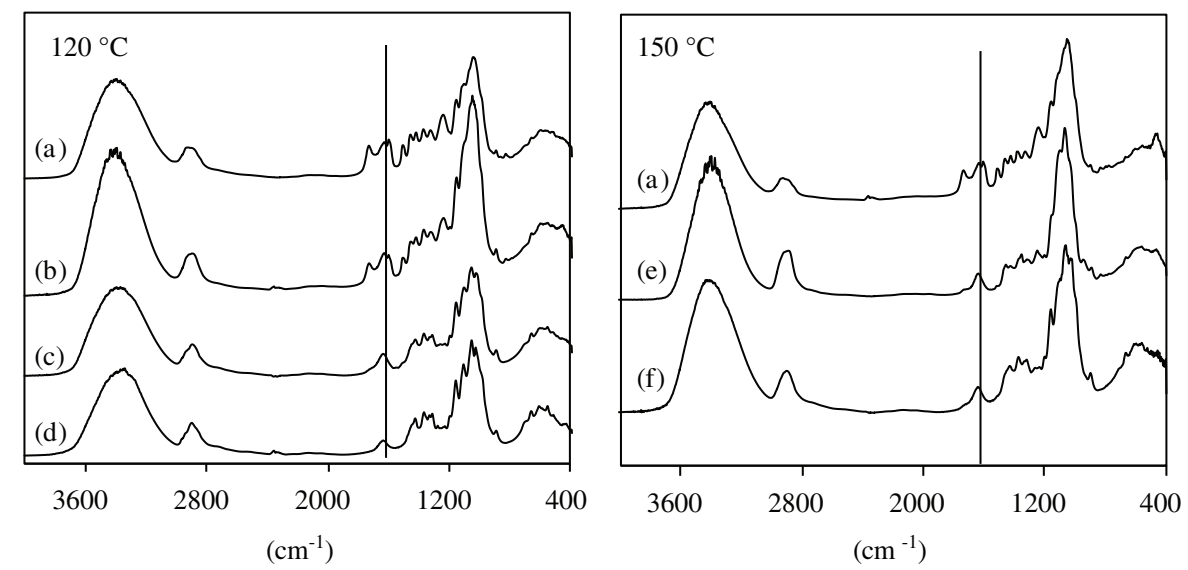

Figure 3: FT-IR spectrometer analysis of liquefied bamboo at $120^{\circ} \mathrm{C}$ and $150^{\circ} \mathrm{C}$. (a) Bamboo; (b) liquefied sample in $5 \mathrm{~min}$; (c) liquefied sample in $15 \mathrm{~min}$; (d) liquefied sample in $30 \mathrm{~min}$; (e) liquefied sample in $5 \mathrm{~min}$; (f) liquefied sample in $30 \mathrm{~min}$. 
lignin concentration were much more than that in the untreated residues at the beginning of reaction where only few lignins were present in the residues, and this could confirm that acid decomposition of lignin was faster than cellulose decomposition.

For the detailed information of spectra, the absorption band from $3500 \mathrm{~cm}^{-1}$ to $3100 \mathrm{~cm}^{-1}$ assigned as hydroxide, the band of bamboo LR at $2908 \mathrm{~cm}^{-1}$, and $2907 \mathrm{~cm}^{-1}$ was assigned as $\mathrm{CH}$ and $\mathrm{CH}_{2}$ stretching vibration of aliphatic hydrocarbons. Two small peaks at $1743 \mathrm{~cm}^{-1}$ and $1736 \mathrm{~cm}^{-1}$ assigned as $\mathrm{C}=\mathrm{O}$ bending, which were attributable to acetyl group or carboxyl group. The strong absorption occurred at $1736 \mathrm{~cm}^{-1}$, which was occurred in spectra of bamboo and $5 \mathrm{~min}$ LR disappeared in the spectra of LR as the reaction proceeded. This result was signified evidence to prove that lignin was liquefied faster than cellulose. The band at $1716 \mathrm{~cm}^{-1}$ assigned as $\mathrm{C}=\mathrm{O}$, which was attributable to carboxyl group stretching conjugated carbonyl group. Two obvious peaks at $1600 \mathrm{~cm}^{-1}$ and $1510 \mathrm{~cm}^{-1}$ assigned as $\mathrm{C}=\mathrm{C}$ bending, which were attributable to the aromatic ring of the lignin. Another important band at $1151 \mathrm{~cm}^{-1}$ assigned as $\mathrm{C}-\mathrm{O}-\mathrm{C}$, which was attributable to $\mathrm{C}-\mathrm{O}-\mathrm{C}$ symmetric stretching vibration of lignin $\beta-\mathrm{O}-4$ ether bond.

\subsubsection{Changes in crystal structure of bamboo during liquefied process}

The XRD have been used widely to evaluate the physico-chemical properties of cellulose and biomass. The apparent Cr.I was calculated from the ratio of the height of the 002 peak $\left(\mathrm{I}_{002}\right)$ and the minimum height of $\left(\mathrm{I}_{\mathrm{am}}\right)$.

The estimation of the value of $I_{a m}$ was also considered by this method [26]. XRD gave the direct results and useful information to explain the structural change in bamboo and liquefied bamboo. Generally, macro- and micro-structure and especially the degree of crystallinity were changed drastically by changing the liquefaction conditions. In this study, the highest peak of 002 was increased obviously after the reaction (Fig. 4). This was another result to prove the reaction process. A clear weak shoulder peak suggests the disturbance in the arrangement of cellulose chains within the hydrogen-banded sheets after $15 \mathrm{~min}$. The apparent Cr.I of bamboo was 55, which then increased to 71 at the initial liquefaction process and back to 62 due to degradation of cellulose in the crystalline region. It could be concluded that the rapid liquefaction stage could be attributed to the components in the bamboo, including lignin in PEG solvent at the first stage of the liquefaction process. However,

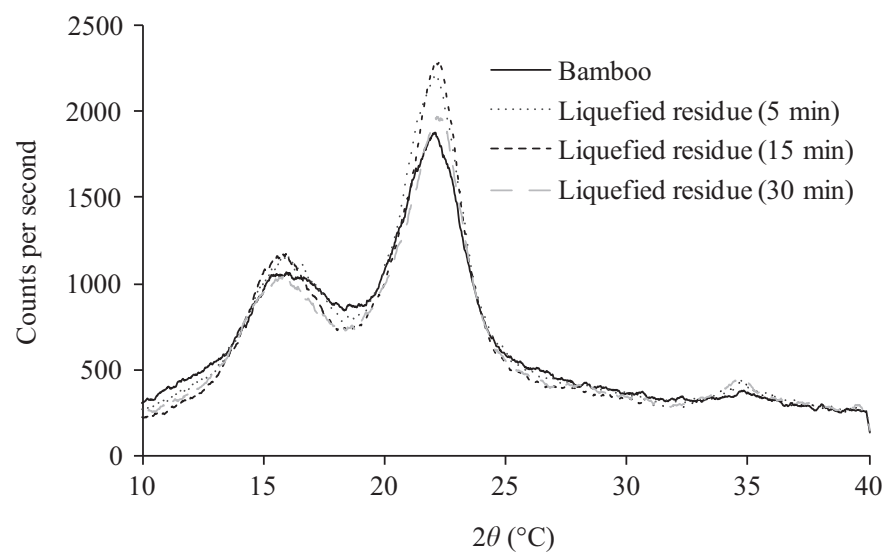

Figure 4: X-ray diffractograms of liquefied bamboo residues related to reaction time within $30 \mathrm{~min}$ at $120^{\circ} \mathrm{C}$ (bamboo:PEG $=1: 4$, sulfuric acid $5 \mathrm{wt} \%$ ). 
no evidence could be proved that the change occurred in the amorphous regions compared with the results of the wood liquefaction reaction [23]. It was not obviously decreased due to the amorphous regions $\left(2 \theta=18.5^{\circ} \mathrm{C}\right)$. The second stage mainly depended on the degradation of cellulose in the crystalline region. The results of component analysis of liquefied bamboo residues related to the reaction time proved the above result (Fig. 5). The amount of holocellulose content was increased at the initial liquefaction process. Then, cellulose was dehydrated and decomposed in the crystalline region by acid catalysis. Therefore, the XRD technology was applied to determine the liquefaction process by analyzing the change in the cellulose crystalline structure.

3.2.3 Particle size distribution of liquefied waste bamboo samples

There is still no report related to the particle size of LRs. Four different sizes of sieve including 1-0.5 $\mathrm{mm}, 0.5-0.25 \mathrm{~mm}, 0.25-0.125 \mathrm{~mm}$, and $0.125-0.075 \mathrm{~mm}$ were used in this study. Figure 6 shows

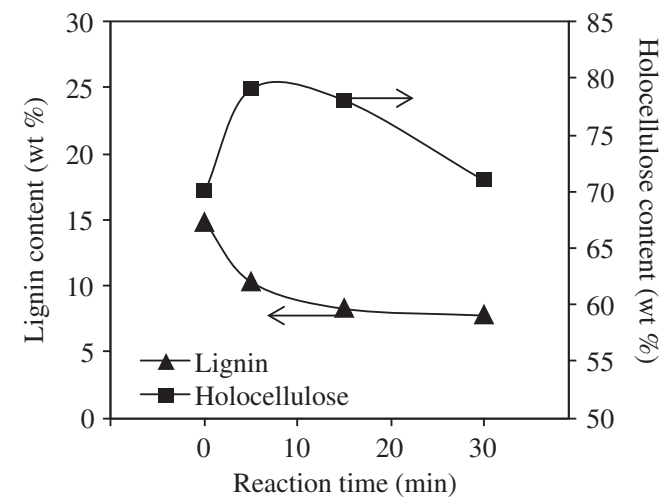

Figure 5: Component analysis of liquefied bamboo residues related to reaction time within $30 \mathrm{~min}$ at $120^{\circ} \mathrm{C}$ (bamboo:PEG = 1:4, sulfuric acid $5 \mathrm{wt} \%$ ).

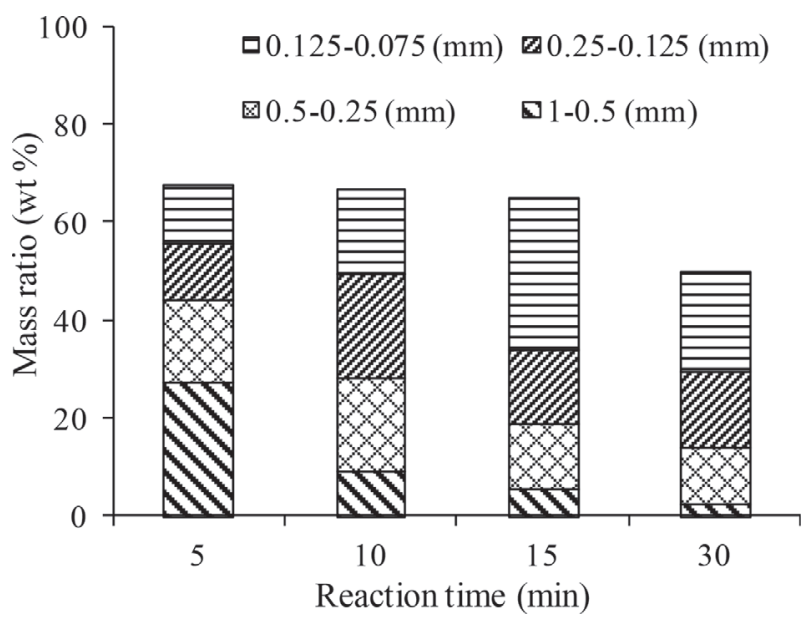

Figure 6: Particle size distribution of liquefied bamboo residues related to reaction time within $30 \mathrm{~min}$ at $120^{\circ} \mathrm{C}$ (bamboo: $\mathrm{PEG}=1: 4$, sulfuric acid $5 \mathrm{wt} \%$ ). 


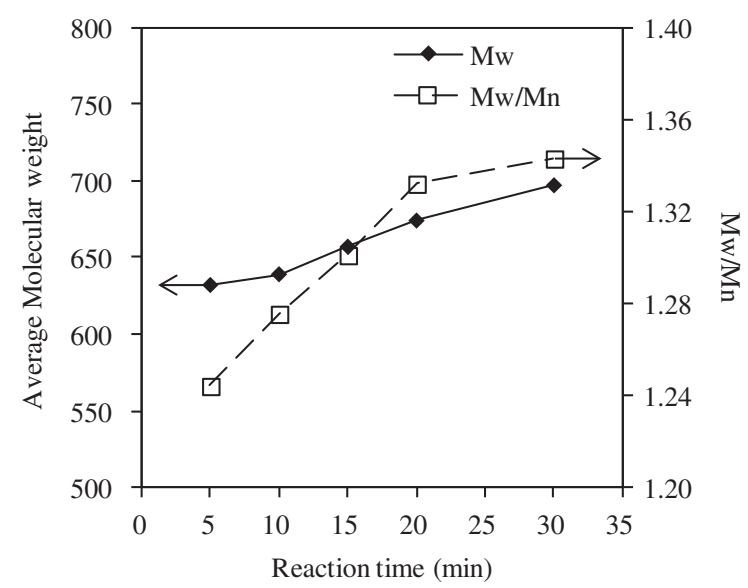

Figure 7: Gel permeation chromatography analysis of liquefied product related to reaction time within $30 \mathrm{~min}$ at $120^{\circ} \mathrm{C}$ (bamboo:PEG $=1: 4$, sulfuric acid $5 \mathrm{wt} \%$ ).

that the particle size, between $1-0.5 \mathrm{~mm}$ and $0.5-0.25 \mathrm{~mm}$, of bamboo was decreased with an increasing in the reaction time. In contrast, the particle size between $0.25-0.125 \mathrm{~mm}$ and 0.125 $0.075 \mathrm{~mm}$ was increased with the reaction time. It is indicated that the high crystalline regions of the cellulose might be appeared mainly due to the composition of this particle size. This result could be used in efficient application to remove the residues for preparing biomass-based material or selected the liquefied product at the different reaction stage.

\subsection{Molecular weight distribution of liquefied product}

As shown in Fig. 7, the average molecular weight of liquefied product was increased with an increase in the reaction time. It was clear that the liquefied products were composed of high molecular compounds, because the average molecular weights (polydispersity $(\mathrm{Mw} / \mathrm{Mn})$ ) of the liquefied products were increased [27]. This indicated that the condensation reaction [28] might occur at the beginning of reaction due to the presence of the compounds.

\section{CONCLUSIONS}

In this study, waste bamboo samples were liquefied in the PEG 400 liquefaction experiment. LRs were measured under the liquefaction condition. The change in the morphological surface was observed by an SEM. The chemical changes in the functional groups in waste bamboo samples were analyzed by an FT-IR spectrometer. The crystalline structures of liquefied bamboo were determined by XRD method. The condensation reaction occurred at the high-temperature liquefaction condition. The condensation reaction might occur at the beginning of reaction due to the presence of liquefied compounds. Therefore, it was suggested the condensation reaction at the lower temperature during the bamboo solvent liquefaction reaction could be prevented by the addition of less amount of acid. The morphological images showed that the liquefied bamboo particles seemed to be not dissolved uniformly. This randomness made the speed of the liquefaction reaction irregular. According to the results of XRD and FT-IR, it is concluded that acid decomposition of lignin was faster than cellulose decomposition. It is also suggested that bamboo could be used for the solvent liquefaction. It is also necessary to consider the heating costs for bamboo with the high crystalline index during its liquefaction since it will need more liquefaction time than those in the usual liquefaction processes. 


\section{ACKNOWLEDGEMENT}

Some works of this study were supported by the special funds for Basic Researches (B) (No. 22303022, FY2010-2012) of Grant-in-Aid Scientific Research of the Japanese Ministry of Education, Culture, Sports, Science and Technology (MEXT), Japan.

\section{REFERENCES}

[1] Yip, J., Chen, M., Szeto, Y.S. \& Yan, S., Comparative study of liquefaction process and liquefied products from bamboo using different organic solvents. Bioresource Technology, 100, pp. 6674-6678, 2009. doi: http://dx.doi.org/10.1016/j.biortech.2009.07.045

[2] Ahmadzadeh, A., Zakaria, S. \& Rashid, R., Liquefaction of oil palm empty fruit bunch (EFB) into phenol and characterization of phenolated EFB resin. Industrial Crops and Products, 30, pp. 54-58, 2009. doi: http://dx.doi.org/10.1016/j.indcrop.2009.01.005

[3] Hassan, E.M. \& Shukry, N., Polyhydric alcohol liquefaction of some lignocellulosic agricultural residues. Industrial Crops and Products, 27, pp. 33-38, 2008. doi: http://dx.doi. org/10.1016/j.indcrop.2007.07.004

[4] Kurimoto, Y., Takeda, M., Doi, S., Tamura, Y. \& Ono, H., Network structures and thermal properties of polyurethane films prepared from liquefied wood. Bioresource Technology, 77, pp. 33-40, 2001. doi: http://dx.doi.org/10.1016/S0960-8524(00)00136-X

[5] Lin, L.Z., Yao, Y.G., Yoshida, M. \& Shiraishi, N., Liquefaction mechanism of cellulose in the presence of phenol under acid catalysis. Carbohydrate Polymers, 57, pp. 123-129, 2004. doi: http://dx.doi.org/10.1016/j.carbpol.2004.01.014

[6] Lee, W.J. \& Chen, Y.C., Novolak PF resins prepared from phenol liquefied Cryptomeria japonica and used in manufacturing moldings. Bioresource Technology, 99, pp. 7247-7254, 2008. doi: http://dx.doi.org/10.1016/j.biortech.2007.12.060

[7] Izumo, K. \& Fukushima, M., Influence of wood species on the properties of biopolyurethane prepared from liquefied wood with residue. Journal of Applied Polymer Science, 118, pp. 2109-2115, 2010.

[8] Wang, H. \& Chen, H.Z., A novel method of utilizing the biomass resource: rapid liquefaction of wheat straw and preparation of biodegradable polyurethane foam (PUF). Journal of the Chinese Institute of Chemical Engineers, 38, pp. 95-102, 2007. doi: http://dx.doi.org/10.1016/j. jcice.2006.10.004

[9] Krzan, A. \& Zagar, E., Microwave driven wood liquefaction with glycols. Bioresource Technology, 100, pp. 3143-3146, 2009. doi: http://dx.doi.org/10.1016/j.biortech.2009.01.057

[10] Krzan, A. \& Kunaver, M., Microwave heating in wood liquefaction. Journal of Applied Polymer Science, 101, pp. 1051-1056, 2005. doi: http://dx.doi.org/10.1002/app.23488

[11] Lee, S.H. \& Ohkita, T., Rapid wood liquefaction by supercritical phenol. Wood Science and Technology, 37, pp. 29-38, 2003. doi: http://dx.doi.org/10.1007/s00226-003-0167-7

[12] Zhang, Y.C., Ikeda, A., Hori, N., Takemara, A., Ono, H. \& Yamada, T., Characterization of liquefied product from cellulose with phenol in the presence of sulfuric acid. Bioresource Technology, 97, pp. 313-321, 2006. doi: http://dx.doi.org/10.1016/j.biortech.2005.02.019

[13] Kobayashi, M., Asano, T., Kajiyama, M. \& Tomita, B., Analysis on residue formation during wood liquefaction with polyhydric alcohol. Journal of Wood Science, 50, pp. 407-414, 2004. doi: http://dx.doi.org/10.1007/s10086-003-0596-9

[14] Niu, M., Zhao, G.J. \& Alma, M.H., Polycondensation reaction and its mechanism during lignocellulosic liquefaction by an acid catalyst. Forestry Studies in China, 13, pp. 71-79, 2011. doi: http://dx.doi.org/10.1007/s11632-011-0109-7 
[15] Pan, H., Synthesis of polymers from organic solvent liquefied biomass: a review. Renewable \& Sustainable Energy Reviews, 15, pp. 3454-3463, 2011. doi: http://dx.doi.org/10.1016/j. rser.2011.05.002

[16] Wang, Q., Qiao, Q., Chen, Q., Mitsumura, N., Kurokawa, H., Sekiguchi, K. \& Sugiyama, K., Process analysis of waste bamboo materials using solvent liquefaction. WIT Transactions on Ecology and the Environment, Vol. 176, Energy and Sustainability IV, eds. C.A. Brebbia, A.M. Marinov, A.A. Mammoli \& C.A. Safta, WIT Press: Southampton, pp. 267-277, 2013.

[17] The Japan Wood Research Society, Wood Scientific Experiments Manual, Buneido Publishing Co., Ltd: Kyoto, Japan, pp. 92-97, 2008.

[18] Nishiyama, Y., Kuga, S. \& Okano, T., Mechanism of mercerization revealed by X-ray diffraction. Journal of Wood Science, 46, pp. 452-457, 2000. doi: http://dx.doi.org/10.1007/ BF00765803

[19] Chen, H. \& Yokochi, A., X-ray diffractometric study of microcrystallite size of naturally colored cottons. Journal of Applied Polymer Science, 76, pp. 1466-1471, 2000. doi: http:// dx.doi.org/10.1002/(SICI)1097-4628(20000531)76:9<1466::AID-APP10>3.0.CO;2-Q

[20] Kobayashi, M., Asano, T., Kajiyama, M. \& Tomita, B., Effect of ozone treatment of wood on its liquefaction. Journal of Wood Science, 51, pp. 348-356, 2005. doi: http://dx.doi.org/10.1007/ s10086-004-0664-9

[21] Yamada, T., Hu, Y. \& Ono, H., Condensation reaction of degraded lignocellulose during wood liquefaction in the presence of polyhydric alcohols. Journal of the Adhesion Society of Japan, 37(12), pp. 471-478, 2001.

[22] Yamada, T. \& Ono, H., Characterization of the products resulting from ethylene glycol liquefaction of cellulose. Journal of Wood Science, 47, pp. 458-464, 2001. doi: http://dx.doi. org/10.1007/BF00767898

[23] Zhang, H.R., Pang, H., Shi, J.Z., Fu, T.Z. \& Liao, B., Investigation of liquefied wood residues based on cellulose, hemicelluloses, and lignin. Journal of Applied Polymer Science, 123, pp. 850-856, 2012. http://dx.doi.org/10.1002/app.34521

[24] Lee, W.J. \& Lin, M.S., Preparation and application of polyurethane adhesives made from polyhydric alcohol liquefied Taiwan Acacia and China Fir. Journal of Applied Polymer Science, 109, pp. 23-31, 2008. doi: http://dx.doi.org/10.1002/app.28007

[25] Chen, F. \& Lu, Z., Liquefaction of wheat straw and preparation of rigid polyurethane foam from the liquefaction products. Journal of Applied Polymer Science, 111, pp. 508-516, 2009. doi: http://dx.doi.org/10.1002/app.29107

[26] Park, S., Baker, J.O., Himmel, M.E., Parilla, P.A. \& Johnson, D.K., Cellulose crystallinity index: measurement techniques and their impact on interpreting cellulase performance. Biotechnology for Biofuels, 3, pp. 10-17, 2010. doi: http://dx.doi.org/10.1186/1754-6834-3-10

[27] Mun, S.P. \& Jang, J.P., Liquefaction of cellulose in the presence of phenol using p-toluene sulfonic acid as a catalyst. Journal of Industrial and Engineering Chemistry, 15, pp. 743-747, 2009. doi: http://dx.doi.org/10.1016/j.jiec.2009.09.056

[28] Wang, Q., Chen, Q., Apaer, P., Kashiwagi, N. \& Guo, X., Liquefaction processes and characterization of liquefied products from waste woody materials in different acidic catalysts. WIT Transactions on Ecology and the Environment, Vol. 176, The Sustainable World, ed. C.A. Brebbia, WIT Press: Southampton, pp. 343-354, 2010. 